\title{
What do foraging wasps optimize in a variable environment, energy investment or body temperature?
}

\author{
Helmut Kovac $^{1} \cdot$ Anton Stabentheiner $^{1} \cdot$ Robert Brodschneider $^{1}$
}

Received: 18 November 2014 / Revised: 28 July 2015 / Accepted: 29 July 2015 / Published online: 19 August 2015

(C) The Author(s) 2015. This article is published with open access at Springerlink.com

\begin{abstract}
Vespine wasps (Vespula sp.) are endowed with a pronounced ability of endothermic heat production. To show how they balance energetics and thermoregulation under variable environmental conditions, we measured the body temperature and respiration of sucrose foragers (1.5 M, unlimited flow) under variable ambient temperature $\left(T_{\mathrm{a}}=20-35^{\circ} \mathrm{C}\right)$ and solar radiation $\left(20-570 \mathrm{~W} \mathrm{~m}^{-2}\right)$. Results revealed a graduated balancing of metabolic efforts with thermoregulatory needs. The thoracic temperature in the shade depended on ambient temperature, increasing from $\sim 37$ to $39{ }^{\circ} \mathrm{C}$. However, wasps used solar heat gain to regulate their thorax temperature at a rather high level at low $T_{\mathrm{a}}$ (mean $T_{\text {thorax }} \sim 39^{\circ} \mathrm{C}$ ). Only at high $T_{\mathrm{a}}$ they used solar heat to reduce their metabolic rate remarkably. A high body temperature accelerated the suction speed and shortened foraging time. As the costs of foraging strongly depended on duration, the efficiency could be significantly increased with a high body temperature. Heat gain from solar radiation enabled the wasps to enhance foraging efficiency at high ambient temperature $\left(T_{\mathrm{a}}=30^{\circ} \mathrm{C}\right)$ by up to $63 \%$. The well-balanced change of economic strategies in response to environmental conditions minimized costs of foraging and optimized energetic efficiency.
\end{abstract}

Electronic supplementary material The online version of this article (doi:10.1007/s00359-015-1033-4) contains supplementary material, which is available to authorized users.

Helmut Kovac

helmut.kovac@uni-graz.at

Anton Stabentheiner

anton.stabentheiner@uni-graz.at

1 Institute of Zoology, University of Graz, Universitätsplatz 2, 8010 Graz, Austria
Keywords Energetics · Thermoregulation · Foraging · Wasps · Vespula

\section{Introduction}

Vespine wasps are heterothermic insects, which are able to switch between an ectothermic and an endothermic state. Their ability of endothermic heat production has been investigated by several authors (e.g. Heinrich 1984; Coelho and Ross 1996; Eckles et al. 2008; Kovac and Stabentheiner 1999, 2012; Kovac et al. 2009). Endothermic heat production by means of the thoracic flight muscles is used for social thermoregulation inside the nest (Steiner 1930; Ishay and Ruttner 1971; Ishay 1973; Klingner et al. 2005, 2006) and also during foraging outside (Eckles et al. 2008; Kovac and Stabentheiner 1999, 2012; Kovac et al. 2009). Foraging vespine wasps are often highly endothermic because their flight muscles must achieve a minimum threshold temperature for proper take off and flight (e.g. Heinrich 1984, 1993; Coelho and Ross 1996; Kovac and Stabentheiner 2012). They can reach thoracic temperatures higher than $40^{\circ} \mathrm{C}$ (Heinrich 1984; Kovac and Stabentheiner 1999; Kovac et al. 2009).

In water-collecting honeybees, a high thorax temperature enables bees to elevate the temperature of the head to a rather high level and increase suction speed (Kovac et al. 2010). On the other hand, endothermy and a high body temperature mean also high costs. Foraging strategies of social insects balance energy expenditure of individual foragers with the net energetic gains to the colony (e.g. Seeley 1986; Seeley et al. 1991; Varjú and Núñez 1991). During foraging, vespine wasps are exposed to highly variable environmental conditions. In a temperate climate, ambient temperature may range from 2 to $38{ }^{\circ} \mathrm{C}$ (Heinrich 1984, 
1993; Kovac and Stabentheiner 1999, 2012; Kovac et al. 2009). Solar radiation may vary from 20 to $1200 \mathrm{~W} \mathrm{~m}^{-2}$ (Kovac et al. 2009; Kovac and Stabentheiner 2012).

However, variation in ambient air temperature can greatly affect the energy expended by foragers. Thus, some wasps and bees alter their metabolic or thermoregulatory activity rates to respond to changes in ambient temperature (Heinrich 1993; Schmolz et al. 1999). Besides ambient air temperature, the influence of solar radiation on insect thermoregulation is not negligible. Its effect on the body temperature of water foraging vespine wasps (Vespula sp.) has been investigated by Kovac et al. (2009). The body temperature was positively correlated with solar radiation, and the thoracic temperature excess was more pronounced at moderate $\left(T_{\mathrm{a}}=22-28{ }^{\circ} \mathrm{C}\right)$ than at high ambient temperatures $\left(>30^{\circ} \mathrm{C}\right)$. At high $T_{\mathrm{a}}$, the wasps reduced active thermoregulation but kept nevertheless a high body temperature.

For a comprehensive assessment of energetic optimization strategies of foraging insects, it is of great advantage to measure both thermoregulatory behaviour and metabolic rate (Stabentheiner et al. 2012). In honeybee foragers, this allowed new insights into the adaptation of economic strategies to variations of environmental conditions (Stabentheiner et al. 2012; Stabentheiner and Kovac 2014). However, in vespine wasps no investigations on foraging energetics are available. The aim of this study was to combine both body temperature measurement with respiration measurement $\left(\mathrm{CO}_{2}\right.$ production) to assess energetic and thermoregulatory optimization strategies of foraging wasps under field conditions. In detail, we investigated what the foragers actually optimize: Do they use heat gain from solar radiation to elevate their body temperature or for the minimization of their energetic expenditure? Do they optimize energetic efficiency or foraging time, or both? The investigations should enable us to differentiate how wasps adapt their energetic strategy during foraging to different environmental challenges.

\section{Materials and methods}

\section{Location and experimental setup}

Experiments were conducted in September and October 2006 in Gschwendt, in a garden close to an external laboratory facility of the University of Graz, Austria. To measure body temperature, respiration and load weight, ten wasps (Vespula germanica) were marked individually with colour dots on thorax and abdomen. They were trained to collect 1.5 molar sucrose solutions in a respiratory measurement chamber (Fig. 1; 7.9 ml inner volume)
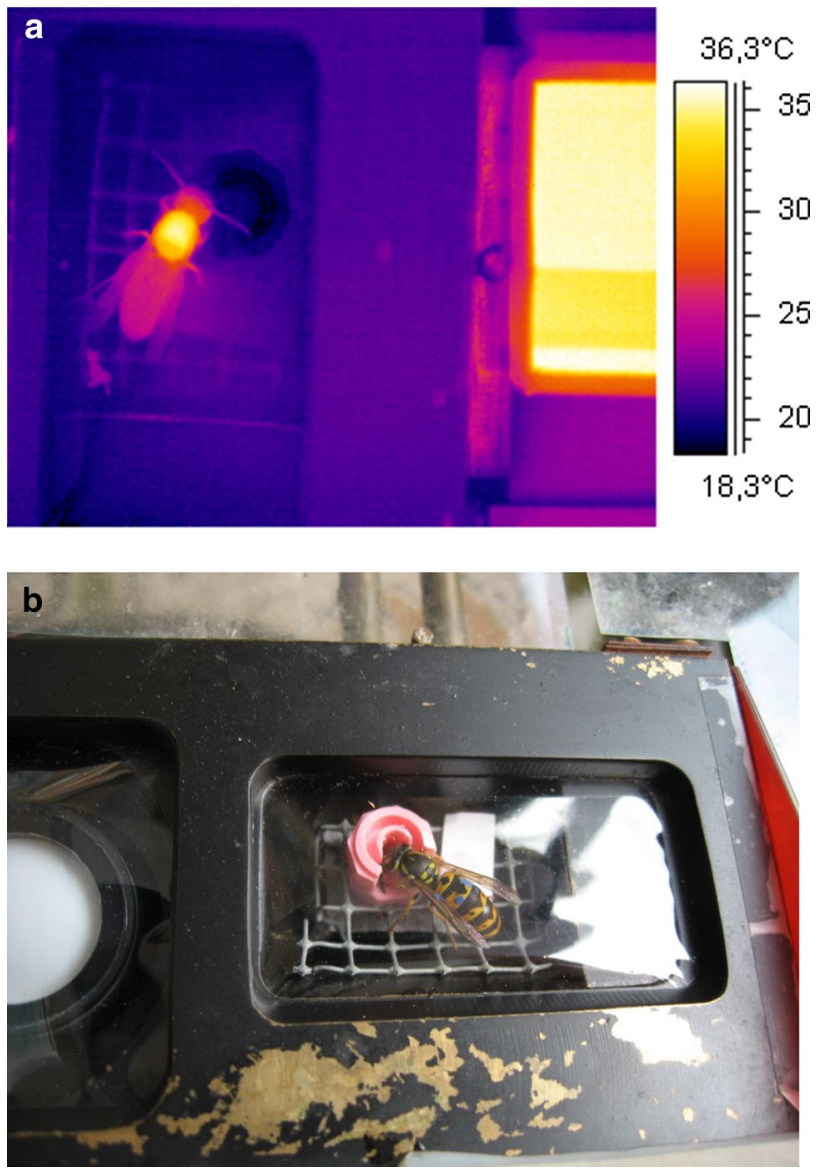

Fig. 1 a Thermogram of a wasp foraging sucrose solution from an artificial flower inside a respiratory measurement chamber. Air inlet is at the bottom of the image, outlet is in the chamber floor right to the wasp. The thorax is heated by activation of the flight muscles, part of the heat has reached the head and the abdomen. $T_{\mathrm{a}} \sim 22{ }^{\circ} \mathrm{C}$. Right-hand rectangle proprietary infrared reference radiator. b Wasp foraging sucrose solution from an artificial flower inside a respiratory measurement chamber. On the left side, the global radiation sensor for measuring the solar radiation is visible

endowed with an artificial flower. The artificial flower was constructed from a cap of a plastic vial as described in Stabentheiner et al. (2012) and Stabentheiner and Kovac (2014). The sucrose solution was offered in this plastic vial where the wasps could suck it. Sucrose solution was delivered unlimitedly to the artificial flower by a perfusor (B-BRAUN Perfusor Compact). To get access to the measurement chamber, the wasps had to pass through a balance (AB104, METTLER-TOLEDO, Greifensee, Switzerland), where they were weighed before and after foraging to measure their load weight. Leaving the balance they had to enter the measurement chamber via a short tunnel. Immediately after entering the chamber, the chamber lid was closed and after finishing sucking the lid was opened manually. During experiments, the chamber was kept closed air tight. 


\section{Ambient temperature and solar radiation in chamber}

Body surface temperature and $\mathrm{CO}_{2}$ production of each individual were measured during 5-10 foraging bouts at the same environmental condition. The variable environmental conditions were ambient air temperature and solar radiation. Experimental ambient temperature in the brass respiratory measurement chamber, which was immersed in a water bath (Julabo F33 HT) for temperature control, was regulated from 20 to $35^{\circ} \mathrm{C}$. If possible, the same wasp was measured both in bright sunshine and artificial shadowing at the same experimental ambient temperature. Sometimes wasps were foraging at intermediate, cloudy conditions. These measurements were also evaluated and taken into consideration. Ambient air temperature was measured about $1 \mathrm{~cm}$ beside the wasps in the measurement chamber by a Type K thermocouple. Solar radiation was measured using a custom-manufactured photoelectric miniature global radiation sensor (FLA613GS/Mini spezial, measurement range of 380-1100 nm; Ahlborn) in a second chamber beside that containing the artificial flower (Stabentheiner et al. 2012; Stabentheiner and Kovac 2014). Air temperature in the measurement chamber, radiation and outside air temperature were recorded with an ALMEMO $^{\circledR}$ data logger (28909; Ahlborn). Results were divided into three categories according to the mean solar radiation during the foraging stay, bright sunshine $\left(>500 \mathrm{~W} \mathrm{~m}^{-2}\right.$, mean $\left.=533 \mathrm{~W} \mathrm{~m}^{-2}\right)$, partial sunshine $\left(100-500 \mathrm{~W} \mathrm{~m}^{-2}\right.$, mean $\left.=398 \mathrm{~W} \mathrm{~m}^{-2}\right)$ and shade $\left(<100 \mathrm{~W} \mathrm{~m}^{-2}\right.$, mean $\left.=20 \mathrm{~W} \mathrm{~m}^{-2}\right)$.

\section{Energy turnover}

The wasps' energy turnover was determined from their $\mathrm{CO}_{2}$ production. $\mathrm{CO}_{2}$ emission was measured using a differential infrared gas analyser (DIRGA; URAS 14, ABB) equipped with a flow-through measurement setup in serial mode. The gas analyser operated at a flow rate of $240 \mathrm{ml} / \mathrm{min}$. Digital data readout via the RS-232 interfaces of the DIRGA was done by Centrol 5 software (Harnisch, Austria). Depending on the experimental situation (ambient temperature and insolation), the rise and decay (washout) times of the $\mathrm{CO}_{2}$ signal resembled or even exceeded the visit duration. Thus, the insects' energy turnover could not be measured by cutting out a section of the respiratory trace and simple averaging. Therefore, we integrated the wasps' total $\mathrm{CO}_{2}$ emission per stay (including 2 min of washout) and divided the integral by the duration of stay inside the respiratory chamber. The loss of measurement gas during chamber opening after the insects' visits was compensated for by calibrations as described in Stabentheiner et al. (2012). Briefly, $\mathrm{CO}_{2}$ was injected into the measurement chamber via a syringe by a perfusor to achieve a stable measurement signal. Then, the perfusor was turned off and the chamber was kept closed, or the perfusor was turned off and the chamber was opened for $\sim 5 \mathrm{~s}$ (the period of chamber opening when a wasp left the chamber). During this period, the chamber was flushed with fresh air because the pump and mass flow controller were still active. This way, we got two calibration curves of the amount of $\mathrm{CO}_{2}$ in the system depending on the 'turnover' (concentration $\times$ flow) at the time of perfusor off. The difference between these two curves represented the $\mathrm{CO}_{2}$ loss caused by chamber opening. For further details concerning the measurement chamber and $\mathrm{CO}_{2}$ measurement, see Stabentheiner et al. (2012). For calculation of the energy gain, the crop load was converted from weight $(\mathrm{mg})$ to volume units, and corrected for density variation due to temperature. Energy gain from sugar was calculated using a calorific value of $16.8 \mathrm{~kJ} / \mathrm{g}$ sucrose (compare Hartfelder et al. 2013). The respiratory quotient was assumed to be 1 as determined by Maschwitz (1966) for resting and moving wasps because they were feeding solely on sucrose solution also in the training period preceding the experiments. The respiratory data were evaluated in MS Excel (Microsoft Corporation) and Origin 8.1/9.1 (OriginLab) software.

\section{Body temperature of foragers}

The lid of the measurement chamber consisted of a brass frame with a plastic film which was transparent to radiation both in the infrared and the visible range (Stabentheiner et al. 2012). This allowed thermographic measurement of the wasps' body surface temperature (FLIR ThermaCam SC2000 NTS) and observation of their behaviour. The infrared camera was calibrated against a proprietary, peltier-driven reference radiator placed within the infrared picture (but not inside the measurement chamber) close to the insects (accuracy $\sim 0.4{ }^{\circ} \mathrm{C}$; Stabentheiner et al. 2012). The attenuation of the infrared radiation by the plastic film was compensated for by covering a part of the reference source head with a stripe of the same film. This also minimized errors resulting from ambient reflections via the film surface. The body surface temperature was calibrated using the cuticular emissivity of honeybees $(e=0.97$; Stabentheiner and Schmaranzer 1987). Thermograms were stored digitally with 14 bit resolution at a rate of $5 \mathrm{~Hz}$ on a DOLCH FlexPac computer (Kontron) with ThermaCam Researcher software (FLIR). Thermographic measurements were evaluated with ThermaCam Researcher software (FLIR) controlled by a proprietary MS Excel (Microsoft) VBA macro. This macro also extracted the stored environmental data automatically from the logger files at the time of thermographic measurement. The thermoregulatory behaviour was evaluated during the whole foraging stay in a way that thermograms were taken every 3-5 s. From these thermograms, the surface temperatures of head, thorax and abdomen, and of the sucrose solution the wasps were collecting, were 
calculated (Fig. 1). Statistics and curve fitting were done with Statgraphics (Stathgraphics Centurion XVI, StatPoint Technology Inc.) and Origin 8.1/9.1 (OriginLab) software.

\section{Data analysis}

We measured the wasps' metabolic rate $\left(\mathrm{CO}_{2}\right.$ release), body temperature, duration of foraging and load weight. The costs and gain of foraging were calculated from metabolic data, foraging time and load weight (see above). We analysed measured and evaluated parameters (metabolic data, thoracic temperature, foraging time, costs and gain of foraging, load weight, efficiency) depending on ambient temperature and solar radiation. Simple linear regressions were performed to show the dependence of parameters on ambient temperature or duration of foraging. The difference between sunshine and shade was tested with Statgraphics (Stathgraphics Centurion XVI, StatPoint Technology Inc.) using an ANOVA.

\section{Results}

\section{Energetics and temperature}

We evaluated 245 foraging stays at the artificial flower in the measurement chamber. From the total of 245 visits, 148 measurements were made in shade, 77 in partial sunshine and 20 in bright sunshine, respectively.

As the wasps differed noticeably in size and weight, the energy turnover and $\mathrm{CO}_{2}$ production were calculated per milligram body weight. The mean energy turnover per stay was in the range of $0.4-1.1 \mathrm{~mW}$ per $\mathrm{mg}(15-83 \mathrm{~mW}$ per wasp). It decreased significantly with increasing ambient temperature $\left(T_{\mathrm{a}}=20-35^{\circ} \mathrm{C} ; p<0.0001\right.$, ANOVA, Fig. 2a). The decrease was smaller in shade $\left(<0.1 \mathrm{~mW} \mathrm{mg}^{-1}\right)$ than in sunshine $\left(\sim 0.5 \mathrm{~mW} \mathrm{mg}^{-1}\right)$. The $\mathrm{CO}_{2}$ release in sunshine did not differ from that in shade at low $T_{\mathrm{a}}$ but was significantly lower at high $T_{\mathrm{a}}$ (Fig. 2a, $p<0.0001$, ANOVA; for further statistical details, see Table 1).

The wasps were endothermic in the entire investigated temperature range $\left(T_{\mathrm{a}}=20-35{ }^{\circ} \mathrm{C}\right.$, Fig. $\left.2 \mathrm{~b}\right)$. The thorax was regulated nearly independently from the ambient during foraging in sunshine ( $T_{\mathrm{th}}=38.6$ in partial sunshine and $\mathrm{T}_{\mathrm{th}}=39.3{ }^{\circ} \mathrm{C}$ in full sunshine; Fig. $2 \mathrm{~b}$ ). In shade, the thoracic temperature increased from 36.6 to $39.8{ }^{\circ} \mathrm{C}$. The regression lines differed significantly between sunny and shaded conditions (Fig. 2b, $p<0.05$, ANOVA; for further statistical details, see Table 1). The temperature of the head and the abdomen, by contrast, depended always clearly on ambient temperature. In the wasps exposed to the sun temperatures of head and abdomen were about $1-3{ }^{\circ} \mathrm{C}$ higher than in the wasps foraging in shade. In some experiments, the wasps came from the cooler ambient outside into the warmer measurement chamber. In these cases, head and abdomen temperature was lower than the ambient temperature inside. The temperature excess over $T_{\mathrm{a}}$ increased in all body parts with decreasing $T_{\mathrm{a}}$. The temperature of the offered sucrose solution $\left(T_{\text {sucrose }}\right)$ in the artificial flower correlated strongly with the temperature $\left(T_{\mathrm{a}}\right)$ in the measurement chamber (online resource 1, shade: $T_{\mathrm{su}}$ crose $=6.71897+0.62859 \times \mathrm{T}_{\mathrm{a}}, n=152$; partial sunshine: $T_{\text {sucrose }}=8.47633+0.64551 \times T_{\mathrm{a}}, n=78$; bright sunshine: $T_{\text {sucrose }}=12.02875+0.50519 \times T_{\mathrm{a}}, n=20$; for all $p<0.0001$, ANOVA).

\section{Duration of foraging stay}

Both in sunshine and in shade, the duration of stay decreased significantly with increasing $T_{\mathrm{a}}$ (Fig. 2c, $p<0.01$, ANOVA; Table 1). In shade, it changed from $\sim 53 \mathrm{~s}$ at $T_{\mathrm{a}}=20{ }^{\circ} \mathrm{C}$ to $\sim 30 \mathrm{~s}$ at $T_{\mathrm{a}}=35^{\circ} \mathrm{C}$. In bright and partial sunshine, the foraging duration was considerably lower than in the shade, in full sunshine decreasing from $\sim 40 \mathrm{~s}$ at $T_{\mathrm{a}}=20{ }^{\circ} \mathrm{C}$ to $\sim 33 \mathrm{~s}$ at $T_{\mathrm{a}}=35{ }^{\circ} \mathrm{C}$. Regression lines from wasps foraging in sunshine differed significantly from those foraging in the shade (Fig. $2 \mathrm{c}, p<0.001$, ANOVA).

\section{Costs of foraging, load weight and efficiency}

The energetic costs of foraging, calculated from the amount of $\mathrm{CO}_{2}$ released during the whole foraging stay and ranging from $\sim 0.7$ to $\sim 5 \mathrm{~J}$, decreased significantly with increasing $T_{\mathrm{a}}$ (Fig. $2 \mathrm{~d}, p<0.0001$, ANOVA; for further statistical details, see Table 1). Values in shade (as derived from the fitted curves in Fig. 2d) amounted to $\sim 3.6 \mathrm{~J}$ at $T_{\mathrm{a}}=20{ }^{\circ} \mathrm{C}$ and $\sim 1.7 \mathrm{~J}$ at $T_{\mathrm{a}}=35^{\circ} \mathrm{C}$, and in bright and partial sunshine to $\sim 2.9$ and $\sim 1.1 \mathrm{~J}$, respectively. The wasps' foraging costs in sunshine were on average $35 \%$ lower as compared to the shade. The regression lines from partial and bright sunshine differed significantly from the regression line of values in shade ( $p<0.0001$, ANOVA) but not from each other. The energetic costs correlated linearly with the duration of foraging (range $~ 20-65$ s; Fig. 3, $p<0.0001$, ANOVA; compare Table 1) but at a lower level in sunshine than in shade $(p<0.01$, ANOVA).

The wasps landing at the balance before drinking sugar solution had an average weight of $76.9 \pm 6.7 \mathrm{mg}(n=245)$. Their mean load weight was $64.6 \pm 9.0 \mathrm{mg}(n=245)$ and did not differ between sunshine and shade. The imbibed amount of sucrose solution was independent of $T_{\mathrm{a}}$ (Fig. 4a, $p>0.05$, ANOVA; see Table 1).

Using the mean load values for calculation, we measured a mean energetic gain per stay of $\sim 467 \mathrm{~J}$ in shade and bright sunshine. The measured costs of $3.6 \mathrm{~J}$ down to $1.7 \mathrm{~J}$ in shade and of $2.9 \mathrm{~J}$ down to $1.1 \mathrm{~J}$ in full sunshine make 

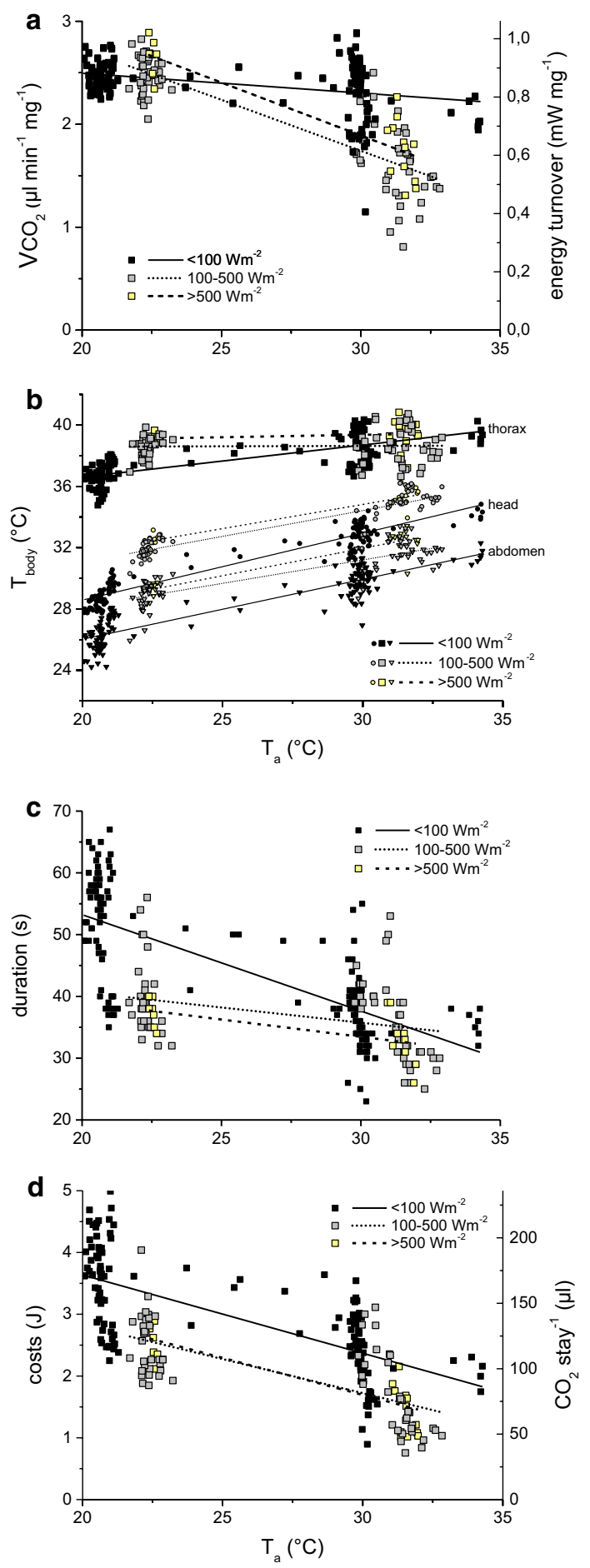

Fig. 2 Energetics and thermoregulation of wasps foraging sucrose solution $(1.5 \mathrm{M})$ in shade (black/filled symbols) and in sunshine (yellow and grey symbols) in dependence on ambient temperature $\left(T_{\mathrm{a}}\right)$. One symbol represents one mean value per stay $(N=148$ in shade (mean radiation $=20 \mathrm{~W} \mathrm{~m}^{-2}$ ), 77 in partial sunshine (mean radiation $=398 \mathrm{~W} \mathrm{~m}^{-2}$ ) and 20 in bright sunshine (mean radiation $=533 \mathrm{~W} \mathrm{~m}^{-2}$ ). a CO 2 production rate $\left(\mathrm{VCO}_{2}\right)$, b body surface temperature of head, thorax and abdomen, $\mathbf{c}$ duration of stay, $\mathbf{d}$ costs per stay, and environmental parameters ( $T_{\mathrm{a}}$ and solar radiation) were measured simultaneously in all individuals. $T_{\mathrm{a}}=$ ambient air temperature near the wasps in the measurement chamber. For constants of linear regression lines and statistics, see Table 1 up only 0.8 to $0.4 \%$ of the harvested gain in shade, and 0.6 to $0.2 \%$ of the gain in the sun, at $T_{\mathrm{a}}=20$ and $35{ }^{\circ} \mathrm{C}$, respectively.

Energetic efficiency (Fig. 4b; gain-costs/costs) (J/J) per stay at our artificial flower was calculated using the loaded sucrose solution (converted to energy gain; Fig. 4a) and the costs (Fig. 2d). Efficiency increased significantly with ambient temperature (Fig. 4b, $p<0.0001$, ANOVA; see Table 1$)$, in shade from $\sim 126$ to $246(\mathrm{~J} / \mathrm{J})$, in partial sunshine from $\sim 133$ to $\sim 388(\mathrm{~J} / \mathrm{J})$, and in bright sunshine from $\sim 123$ to $\sim 402(\mathrm{~J} / \mathrm{J})$ at $T_{\mathrm{a}}=20$ and $35^{\circ} \mathrm{C}$, respectively. The energetic efficiency of wasps foraging in sunny conditions differed significantly from that of wasps foraging in shade (Fig. 4b, $p<0.0001$, ANOVA). While at $T_{\mathrm{a}}=20{ }^{\circ} \mathrm{C}$ the efficiency was not different between sunshine and shade, at $T_{\mathrm{a}}=35^{\circ} \mathrm{C}$ foraging in partial sunshine increased efficiency by $\sim 58 \%$ and in bright sunshine by $\sim 63 \%$ in comparison to shade.

\section{Discussion}

\section{Energy turnover, thermoregulation and environmental variation}

A novel experimental setup allowed the measurement of respiration and body temperature of foraging wasps simultaneously. Results revealed interesting aspects concerning the interactions of thermoregulation and metabolism with changing environmental parameters (ambient temperature and solar radiation). As the wasps foraged from a rather high-quality food source with unlimited flow rate, they exhibited a high energy turnover, similar to honeybees (Stabentheiner and Kovac 2014). At limited flow (lower reward rates), we expect a lower energy turnover (compare e.g. Balderrama et al. 1992; Moffat and Núñez 1997). At lower ambient temperature (Fig. 2a, b; $T_{\mathrm{a}}=20-23{ }^{\circ} \mathrm{C}$ ), the energy turnover was nearly the same in sunshine and in shade, whereas the thoracic temperature was elevated from the sun. This difference in the thoracic temperature diminished in the higher ambient temperature range $\left(T_{\mathrm{a}}=30-35{ }^{\circ} \mathrm{C}\right.$; Fig. $\left.2 \mathrm{a}, \mathrm{b}\right)$. However, the energy turnover decreased remarkably in wasps foraging in sunshine at high ambient temperature (Fig. 2a). This means, using heat gain from solar radiation the wasps could reduce their own energy expenditure and nevertheless keep a high thorax temperature. At lower ambient temperature, by contrast, they did not reduce the heat production (metabolic rate) in the sun but invested solar heat to increase thorax temperature, probably to provide the head with sufficient heat. A high temperature of the head very probably improves the wasps' suction speed. In honeybees, the function of the musculature involved in suction ('suction pump') is 
Table 1 Constants and statistics for regression functions $(y=A+B \times \mathrm{x})$ in Figs. 2, 3 and $4\left(T_{\mathrm{a}}=\right.$ ambient air temperature;

$T_{\text {hd }}, T_{\text {th }}, T_{\text {ab }}=$ temperatures of head, thorax, abdomen. $N=148$ visits in shade (mean radiation $=20 \mathrm{~W} \mathrm{~m}^{-2}$ ), 77 in partial sunshine (mean radiation $=398 \mathrm{~W} \mathrm{~m}^{-2}$ ) and 20 in bright sunshine (mean radiation $=533 \mathrm{~W} \mathrm{~m}^{-2}$ ); ANOVA, linear regression analysis

Constants $F$ value $\quad R^{2} \quad p$

A

B

\begin{tabular}{|c|c|c|c|c|c|}
\hline \multicolumn{6}{|l|}{ Figure $2 \mathrm{a}$} \\
\hline Shade & 2.88019 & -0.01925 & 21.18547 & 0.12074 & $8.98591 \mathrm{E}-6$ \\
\hline Partial sun & 4.71269 & -0.09904 & 196.70772 & 0.72029 & 0 \\
\hline Bright sun & 4.97513 & -0.10282 & 61.68375 & 0.77124 & $4.68678 \mathrm{E}-7$ \\
\hline \multicolumn{6}{|l|}{ Figure $2 b$} \\
\hline \multicolumn{6}{|l|}{$\mathrm{T}_{\mathrm{hd}}$} \\
\hline Shade & 19.86166 & 0.43609 & 1469.02849 & 0.90673 & 0 \\
\hline Partial sun & 24.31604 & 0.33694 & 330.95722 & 0.80683 & 0 \\
\hline Bright sun & 25.37806 & 0.31481 & 133.13551 & 0.87429 & $9.46395 \mathrm{E}-10$ \\
\hline \multicolumn{6}{|l|}{$\mathrm{T}_{\mathrm{th}}$} \\
\hline Shade & 32.42867 & 0.20908 & 188.232 & 0.55356 & 0 \\
\hline Partial sun & 38.49455 & 0.00481 & 0.04325 & -0.01226 & 0.8358 \\
\hline Bright sun & 38.42242 & 0.0314 & 0.508 & -0.02658 & 0.48514 \\
\hline \multicolumn{6}{|l|}{$\mathrm{T}_{\mathrm{ab}}$} \\
\hline Shade & 18.2244 & 0.39041 & 713.46399 & 0.82512 & 0 \\
\hline Partial sun & 22.04058 & 0.30539 & 188.27295 & 0.70331 & 0 \\
\hline Bright sun & 21.24723 & 0.35706 & 102.56424 & 0.84241 & $7.34739 \mathrm{E}-9$ \\
\hline \multicolumn{6}{|l|}{ Figure 2c } \\
\hline Shade & 84.42389 & -1.5598 & 165.16176 & 0.52758 & 0 \\
\hline Partial sun & 50.49998 & -0.49179 & 10.0215 & 0.10611 & 0.00224 \\
\hline Bright sun & 50.21389 & -0.55844 & 10.63431 & 0.34864 & 0.0046 \\
\hline \multicolumn{6}{|l|}{ Figure $2 d$} \\
\hline Shade & 6.172 & -0.12679 & 133.889 & 0.48519 & 0 \\
\hline Partial sun & 5.02698 & -0.11013 & 57.82409 & 0.45523 & $1.24414 \mathrm{E}-10$ \\
\hline Bright sun & 5.29102 & -0.11991 & 34.05476 & 0.64744 & $1.98592 \mathrm{E}-5$ \\
\hline \multicolumn{6}{|l|}{ Figure 3} \\
\hline Shade & -0.45122 & 0.07831 & 664.58918 & 0.82476 & 0 \\
\hline Partial sun & -0.62241 & 0.07412 & 42.74479 & 0.38038 & $1.00764 \mathrm{E}-8$ \\
\hline Bright sun & -2.54825 & 0.13274 & 36.33783 & 0.67519 & $1.75655 \mathrm{E}-5$ \\
\hline \multicolumn{6}{|l|}{ Figure $4 \mathrm{a}$} \\
\hline Shade & 62.05778 & 0.11433 & 0.52297 & -0.0033 & 0.47075 \\
\hline Partial sun & 57.31434 & 0.22121 & 0.80679 & -0.00273 & 0.37215 \\
\hline Bright sun & 49.64381 & 0.554 & 1.80463 & 0.04279 & 0.19681 \\
\hline \multicolumn{6}{|l|}{ Figure $4 b$} \\
\hline Shade & -33.76372 & 8.00786 & 160.87167 & 0.53136 & 0 \\
\hline Partial sun & -207.09197 & 17.00221 & 127.72577 & 0.65079 & 0 \\
\hline Bright sun & -247.93302 & 18.56891 & 42.14643 & 0.69567 & $5.52739 \mathrm{E}-6$ \\
\hline
\end{tabular}

suggested to be strongly dependent on body temperature (Kovac et al. 2010; Stabentheiner and Kovac 2014). Wasps and bees have a different mouthpart morphology. While bees have specialized mouthparts for nectar uptake from blossoms, the mouthparts of wasps have strong mandibles for capturing and chewing insects, and a short proboscis for sucking nectar. Thus, nectar uptake behaviour differs between these two Hymenoptera. This difference could have led to differences in nectar uptake rate as observed in the present setup. The amount of food collected by the wasps (64.6 $\mathrm{mg}$ of $1.5 \mathrm{M}$ sucrose solution) was very similar as compared to honeybees foraging from the same experimental setup $(64.9 \mathrm{mg}$, Stabentheiner and Kovac 2014). However, the velocity of food uptake was 


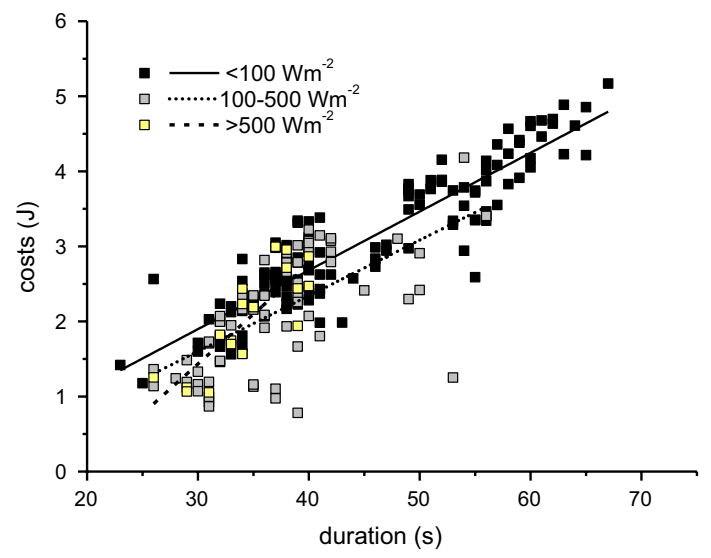

Fig. 3 Dependence of costs per stay on duration of stay in shade and in sunshine. For constants of linear regression lines and statistics, see Table 1. Regression lines significantly different between shade and sunshine ( $p<0.01$, ANOVA). One outlier at $70 \mathrm{~s}$ and $1.043 \mathrm{~J}$ $\left(>500 \mathrm{~W} \mathrm{~m}^{-2}\right.$ ) was excluded from calculation
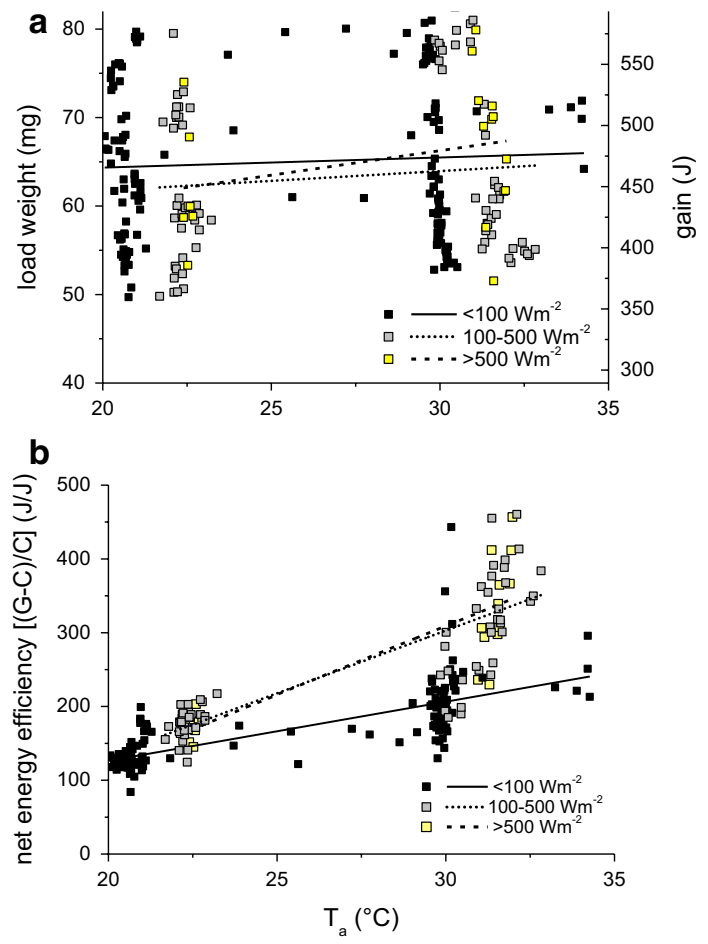

Fig. 4 Load weight and energy gain (a) and net energy efficiency (b) (gain-costs/costs) of foraging wasps in shade and in sunshine depending on ambient temperature $\left(T_{\mathrm{a}}\right)$. For constants of linear regression lines and statistics, see Table 1 . Regression lines significantly different between shade and sunshine $(p<0.0001$, ANOVA) in $\mathbf{b}$ but not in $\mathbf{a}$

remarkably higher in the wasps. The relationship between wasps and bees at $T_{\mathrm{a}}=20^{\circ} \mathrm{C}$ was $53: 84 \mathrm{~s}$ in shade and 40:61 s in sunshine, and at $T_{\mathrm{a}}=30{ }^{\circ} \mathrm{C}$ it was $38: 43 \mathrm{~s}$ in shade and 35:45 s in sunshine. Our measurements are in agreement with the report of Kingsolver and Daniel (1995) that wasps perform better when liquid food is offered on a tray (or as droplet of honeydew), whereas bees perform better when sucking sugar solution from tubular structures like blossoms. These findings are even more surprising as wasps are able to drink faster with a lower thorax temperature and similar head temperature than bees. Though we suggest suction speed to depend on body temperature also in wasps, morphological and physiological differences in the suction apparatus probably account for the higher drinking velocity of the wasps. It has to be kept in mind that differences in viscosity of the sucrose solution at different temperatures might have affected the results. Kinematic viscosity of sugar solutions decreases with increasing ambient temperature (e.g. Chenlo et al. 2002; Galmarini et al. 2011). In our experiments, the temperature of the sucrose solution increased linearly with ambient temperature (see online resource 1). However, even in water foraging honeybees (Kovac et al. 2010), where the viscosity does not increase so strongly with temperature, it could be shown that suction speed depends dramatically on body temperature, especially the temperature of the head. Wasps, like honeybees, invest external heat gain as well as own heat production in a flexible way to keep the body temperature high. This may not only improve the function of the suction apparatus but may also decrease sucrose viscosity during its passage of the structures involved in ingestion.

In ants, environmental temperature modified the dynamics of ingestion and feeding behaviour by directly affecting pumping frequency. The ants' intake rate of sucrose solution increased when ambient temperature and, therefore, body temperature in these poikilothermic insects rose (Falibene and Josens 2014). The wasps, by contrast, can actively accelerate their drinking speed by keeping the thoracic temperature at a high level and rather constant. With this high energetic investment, they are able to reduce foraging time and to perform more foraging flights within the same time, which means that they optimize the rate of food intake from a source of unlimited flow in a similar way as honeybees do (Stabentheiner and Kovac 2014). However, reducing the foraging time is not only important for increasing the individual forager's intake rate and efficiency. Schilman and Roces (2006) investigated nectar feeding ants and postulated that saving time (with the potential increase in colony-wide energy intake via social recruitment) is more important than saving energy (or increasing individual forager efficiency). The income of a high amount of food may stimulate other members in the wasp colony to perform foraging flights (compare Taylor et al. 2012a, b). 
Vespine wasps are endowed with endothermic capabilities similar to honeybees (e.g. Heinrich 1984; Coelho and Ross 1996; Eckles et al. 2008; Kovac and Stabentheiner 1999, 2012; Kovac et al. 2009), and similar to honeybees, foraging motivation modulates the wasps' thermoregulatory activity (Kovac and Stabentheiner 1999; Eckles et al. 2008). As the 1.5 molar sucrose solution is a very highquality food resource at unlimited flow (Kovac and Stabentheiner 1999) and is supposed to be near the optimal concentration for which the energy intake rate is highest based on drinking rates in sucking insects (Kim et al. 2011), the wasps exhibited rather high thorax and body temperatures (Fig. 2b). However, the wasps' thoracic temperature was always about $2-3{ }^{\circ} \mathrm{C}$ lower than in honeybees foraging at similar conditions at the same experimental setup (Stabentheiner and Kovac 2014). Foraging honeybees often exhibit thoracic temperatures higher than $40{ }^{\circ} \mathrm{C}$ on water sources (Kovac et al. 2010) and on an artificial flower (Stabentheiner and Kovac 2014) whereas wasps avoid exceeding a thoracic temperature higher than $40{ }^{\circ} \mathrm{C}$ (unlimited flow of resources in all cases). These differences probably result from considerable differences in the thermal sensitivity of bees and wasps. The critical thermal maximum (activity $\mathrm{CT}_{\max }$ ) of wasps is $4.1{ }^{\circ} \mathrm{C}$ lower than in honeybees (44.9 vs. $49.0^{\circ} \mathrm{C}$; Käfer et al. 2012).

We conclude that Central European Vespula germanica are better adapted to lower temperatures than honeybees both physiologically and behaviourally. With the same or even lower body temperature, they ingest fluids faster, are more agile, and are more than a match for the bees during fights (Stabentheiner et al. 2007). This view is supported by the finding that they regularly forage at ambient temperatures below $10{ }^{\circ} \mathrm{C}$ (Kovac and Stabentheiner 2012), whereas honeybees only do this in case of urgent need for water (Kovac et al. 2010) but never on flowers (Kovac and Schmaranzer 1996; Kovac and Stabentheiner 2011) nor on artificial sucrose feeding places (our own observations).

\section{Costs, gain and efficiency}

Foraging in endothermic insects is very costly. Thus, the balance between energy investment and energy gain is crucial for survival of the colony. The wasps resembled the bees in that their energy turnover in shade was kept rather constant despite considerable variation in $T_{\mathrm{a}}$. However, their lower thoracic temperature allowed them to forage at lower costs. Their energy turnover (in shade) was on average about $0.1 \mathrm{~mW}$ per $\mathrm{mg}(\sim 8 \mathrm{~mW}$ per insect) lower than in honeybee foragers (Stabentheiner and Kovac 2014). It was a surprising finding that despite their lower body temperature, the wasps were able to ingest sucrose solution not only considerably faster but also at lower instantaneous costs (i.e. turnover) than honeybees.
Social insects were believed to optimize energy costs rather than foraging time (Seeley 1994). However, the main parameter determining the costs per foraging stay under our experimental conditions (1.5 molar sucrose solution at unlimited flow) was the foraging time, which was mainly the intake time of the sugar solution until the honey crop was full. The costs increased linearly with the duration of stay (Fig. 3), and both the duration and the costs (amount of $\mathrm{CO}_{2}$ released during the foraging stay) decreased with increasing ambient temperature (Fig. 2c, d). Foraging in sunshine yielded remarkable savings of costs for the wasps. However, it has to be kept in mind that the costs of $3.6 \mathrm{~J}$ down to $1.1 \mathrm{~J}$ (Fig. 2d) make up a rather small fraction of the energy gain of this high-quality resource $(0.8-0.4 \%$ of the harvested gain in shade, and $0.6-0.2 \%$ of the gain in the sun, $T_{\mathrm{a}}=20-35^{\circ} \mathrm{C}$ ).

A measure of the energetic efficiency is the relationship between net gain and costs (gain-costs/costs, Fig. 4b) (e.g. Pyke et al. 1977; Waddington and Holden 1979; SchmidHempel et al. 1985; Seeley 1986, 1994; Schmid-Hempel and Schmid-Hempel 1987). At low ambient temperature, efficiency was nearly the same in sunshine and in shade. The wasps invested solar heat to increase their body temperature, which in turn increased suction speed. They made use of a similar 'investment-guided' strategy as reported for honeybees (Stabentheiner and Kovac 2014). The additional investment enables more foraging flights per time interval and an increased intake rate and net gain for the colony. At high ambient temperatures $\left(T_{\mathrm{a}}=30{ }^{\circ} \mathrm{C}\right)$, by contrast, net energetic efficiency was up to $63 \%$ higher under sunny conditions (Fig. 4b), although the loaded weight was similar for all environmental conditions (Fig. 4a). In this case, the wasps followed an 'economizing' strategy (Stabentheiner and Kovac 2014). As they could not accelerate suction speed any more, probably because they were already rather close to their upper thermal limit, they reduced their energy turnover, which saved about $35 \%$ of energetic costs per stay (Fig. 2d). For comparison, in honeybees efficiency during foraging in the sun was $\sim 22 \%$ to $\sim 71 \%$ higher than in shade $\left(T_{\mathrm{a}}=20-30{ }^{\circ} \mathrm{C}\right.$; Stabentheiner and Kovac 2014). In both wasps and bees, the high efficiency was accomplished by a flexible physiological and behavioural strategy of energetic investment and use of external (solar) heat. Differences between the two species may at least in part result from different mean solar radiation values in the experiments, and a different solar heat gain due to the wasps' different pigmentation and density of hairs on the body surface.

We conclude that foraging wasps optimize costs in a similar way than honeybees. These two species use the same flexible energetic strategy to maximize intake rate and optimize foraging efficiency at sources of unlimited flow. Flexible energetic management optimizes body 
temperature, which in turn shortens the foraging time. This optimization of foraging time then optimizes gain and costs of the individual, which in turn maximizes the net energy gain per time interval (intake rate) of the colony. The wasps, however, achieve this with lower energetic expenditure and body temperature.

Acknowledgments The research was funded by the Austrian Science Fund (FWF): P16584-B06, P20802-B16, P25042-B16. We greatly appreciate the help with data evaluation by $\mathrm{M}$. Ablasser and $\mathrm{S}$. Hashold, and of W. Schühly for reviewing the language of the manuscript. Thanks to an anonymous reviewer who provided very useful comments.

Open Access This article is distributed under the terms of the Creative Commons Attribution 4.0 International License (http://creativecommons.org/licenses/by/4.0/), which permits unrestricted use, distribution, and reproduction in any medium, provided you give appropriate credit to the original author(s) and the source, provide a link to the Creative Commons license, and indicate if changes were made.

\section{References}

Balderrama NM, Almeida LO, Núñez JA (1992) Metabolic rate during foraging in the honey bee. J Comp Physiol B 162:440-447

Chenlo F, Moreira R, Pereira G, Ampudia A (2002) Viscosities of aqueous solutions of sucrose and sodium chloride of interest in osmotic dehydration processes. J Food Eng 54:347-352

Coelho JR, Ross AJ (1996) Body temperature and thermoregulation in two species of yellowjackets, Vespula germanica and V. maculifrons. J Comp Physiol B 166:68-76

Eckles MA, Wilson EE, Holway DA, Nieh JC (2008) Yellowjackets (Vespula pensylvanica) thermoregulate in response to changes in protein concentration. Naturwissenschaften 95:787-792

Falibene A, Josens R (2014) Environmental temperature affects the dynamics of ingestion in the nectivorous ant Camponotus mus. $\mathbf{J}$ Insect Physiol 71:14-20

Galmarini MV, Baeza R, Sanchez V, Zamora MC, Chirife J (2011) Comparison of the viscosity of trehalose and sucrose solutions at various temperatures: effect of guar gum addition. LWT Food Sci Tech 44:186-190

Hartfelder K, Bitondi MMG, Brent C, Guidugli-Lazzarini KR, Simões ZLP, Stabentheiner A, Tanaka DE, Wang Y (2013) Standard methods for physiology and biochemistry research in Apis mellifera. J Apic Res 52:26-47. (In: Dietemann V, Ellis JD, Neumann P (Eds) The COLOSS BEEBOOK, Volume I: standard methods for Apis mellifera research"). doi:10.3896/ IBRA.1.52.1.06

Heinrich B (1984) Strategies of thermoregulation and foraging in two vespid wasps, Dolichovespula maculata and Vespula vulgaris. J Comp Physiol B 154:175-180

Heinrich B (1993) The hot-blooded insects. Springer, Berlin

Ishay JS (1973) Thermoregulation by social wasps: behaviour and pheromones. Trans N Y Acad Sci 35:447-462

Ishay JS, Ruttner F (1971) Thermoregulation im Hornissennest. Z vergleich Physiol 72:423-434

Käfer H, Kovac H, Stabentheiner A (2012) Resting metabolism and critical thermal maxima of vespine wasps (Vespula sp.). J Insect Physiol 58:679-689

Kim W, Gilet T, Bush JWM (2011) Optimal concentrations in nectar feeding. PNAS 108:16618-16621
Kingsolver JG, Daniel TL (1995) Mechanics of food handling by fluid-feeding insects. In: Chapman RF, de Boer G (eds) Regulatory mechanisms in insect feeding. Springer Science + Business Media, Dordrecht, pp 32-73

Klingner R, Richter K, Schmolz E, Keller B (2005) The role of moisture in the nest thermoregulation of social wasps. Naturwissenschaften 92:427-430

Klingner R, Richter K, Schmolz E (2006) Strategies of social wasps for thermal homeostasis in light paper nests. J Therm Biol 31:599-604

Kovac H, Schmaranzer S (1996) Thermoregulation of honeybees (Apis mellifera) foraging in spring and summer at different plants. J Insect Physiol 42:1071-1076

Kovac H, Stabentheiner A (1999) Effect of food quality on the body temperature of wasps (Paravespula vulgaris). J Insect Physiol 45:183-190

Kovac H, Stabentheiner A (2011) Thermoregulation of foraging honeybees on flowering plants: seasonal variability and influence of radiative heat gain. Ecol Entomol 36:686-699

Kovac H, Stabentheiner A (2012) Does size matter?-Thermoregulation of 'heavyweight' and 'lightweight' wasps (Vespa crabro and Vespula sp.). Biol Open 1:848-856

Kovac H, Stabentheiner A, Schmaranzer S (2009) Thermoregulation of water foraging wasps (Vespula vulgaris and Polistes dominulus). J Insect Physiol 55:959-966

Kovac H, Stabentheiner A, Schmaranzer S (2010) Thermoregulation of water foraging honeybees-balancing of endothermic activity with radiative heat gain and functional requirements. J Insect Physiol 56:1834-1845

Maschwitz U (1966) Das Speichelsekret der Wespenlarven und seine biologische Bedeutung. Z vergl Physiol 53:228-252

Moffat L, Núñez JA (1997) Oxygen consumption in the foraging honeybee depends on the reward rate at the food source. J Comp Physiol B 167:36-42

Pyke GH, Pulliam HR, Charnov EL (1977) Optimal foraging: a selective review of theory and tests. Quart Rev Biol 52:137-154

Schilman PE, Roces F (2006) Foraging energetics of a nectar-feeding ant: metabolic expenditure as a function of food-source profitability. J Exp Biol 209:4091-4101

Schmid-Hempel P, Schmid-Hempel R (1987) Efficient nectar-collecting by honeybees II. Response to factors determining nectar availability. J Anim Ecol 56:219-227

Schmid-Hempel P, Kacelnik A, Houston AJ (1985) Honeybees maximize efficiency by not filling their crop. Behav Ecol Sociobiol 17:61-66

Schmolz E, Brüders N, Schricker B, Lamprecht I (1999) Direct calorimetric measurement of heat production rates in flying hornets (Vespa crabro; Hymenoptera). Thermochim Acta 328:3-8

Seeley TD (1986) Social foraging by honeybees: how colonies allocate foragers among patches of flowers. Behav Ecol Sociobiol 19:343-354

Seeley TD (1994) Honeybee foragers as sensory units of their colonies. Behav Ecol Sociobiol 34:51-62

Seeley TD, Camazine S, Sneyd J (1991) Collective decision-making in honey bees: how colonies choose among nectar sources. Behav Ecol Sociobiol 28:277-290

Stabentheiner A, Kovac H (2014) Energetic optimisation of foraging honeybees: flexible change of strategies in response to environmental challenges. PLoS ONE 9:e105432

Stabentheiner A, Schmaranzer S (1987) Thermographic determination of body temperatures in honey bees and hornets: calibration and applications. Thermology 2:563-572

Stabentheiner A, Kovac H, Schmaranzer S (2007) Thermal behaviour of honeybees during aggressive interactions. Ethology 113:995-1006 
Stabentheiner A, Kovac H, Hetz SK, Käfer H, Stabentheiner G (2012) Assessing honeybee and wasp thermoregulation and energetics-new insights by combination of flow through respirometry with infrared thermography. Thermochim Acta 534:77-86. doi:10.1016/j.tca.2012.02.006

Steiner A (1930) Die Temperaturregulierung im Nest der Feldwepe (Polistes gallica var. biglumis L.). Z vergl Physiol 11:461-502

Taylor BJ, Nordheim EV, Jeanne RL (2012a) Allocation of colonylevel foraging effort in Vespula germanica in response to food resource quantity, quality, and associated olfactory cues. Ethology 118:594-605

Taylor BJ, Brus EJ, Jeanne RL (2012b) Introduction of a scented carbohydrate resource into the nest increases departure rate in Polybia occidentalis. Insect Soc 59:151-157

Varjú D, Núñez JA (1991) What do foraging honeybees optimize? J Comp Physiol A 169:729-736

Waddington KD, Holden LD (1979) Optimal foraging: on flower selection by bees. Am Nat 114:179-196 